\title{
PREVALENCE OF CHRONIC OBSTRUCTIVE PULMONARY DISEASE IN PATIENTS WITH CORONARY HEART DISEASE AND ARTERIAL HYPERTENSION
}

\author{
Lesya Rasputina \\ Department of propaedeutics of internal medicine \\ National Pirogov Memorial Medical University \\ 56 Pirogova str., Vinnytsya, Ukraine, 21018 \\ rasputina.l@mail.ru \\ Daria Didenko \\ Department of propaedeutics of internal medicine \\ National Pirogov Memorial Medical University \\ 56 Pirogova str., Vinnytsya, Ukraine, 21018 \\ larchyk@gmail.com
}

\begin{abstract}
The prevalence of chronic obstructive pulmonary disease among patients with cardio-vascular diseases is higher than in general population. At the same time the one of problems of internal medicine is a timely diagnostics of chronic obstructive pulmonary disease.

The aim of the work was the study of prevalence of chronic obstructive pulmonary disease among patients with cardio-vascular diseases, especially arterial hypertension and coronary heart disease.

Materials and methods. The retrospective analysis of statistical cards of patients, who were on stationary treatment at therapeutic departments, was carried out to estimate the prevalence of combination of chronic obstructive pulmonary disease with arterial hypertension. The target examination of 136 patients was realized for revelation of chronic obstructive pulmonary disease. All patients were interrogated by the original modified questionnaire of assessment of short breath by medical research council (mMRC), test for assessment of chronic obstructive pulmonary disease (CAT) and underwent spirography with bronchodilatation test.

Results. It was established, that $10,2 \%$ of patients had the combination of chronic obstructive pulmonary disease with arterial hypertension. Among persons, who were on treatment as to the stable coronary heart disease and had not obstructive disease of respiratory organs in anamnesis, in $26,4 \%$ the chronic obstructive pulmonary disease was diagnosed for the first time.

Keywords: chronic obstructive pulmonary disease, comorbid pathology, arterial hypertension, coronary heart disease, diagnostics.

\section{Introduction}

The disease of respiratory organs and the ones of cardio-vascular system are often destined for co-existence. They often start at the same age, have common proved risk factors, series of similar pathophysiological mechanisms, namely: chronic hypoxia, rheological changes of blood and so on. It must be noted that essential ageing of the planet population resulted in increase of the number of persons, who have chronic diseases of respiratory organs, including chronic obstructive pulmonary disease and cardio-vascular diseases, first of all, arterial hypertension and coronary heart disease [1-3].

The prevalence of chronic obstructive pulmonary disease in the world among men and women is $9,3 \%$ and $7,3 \%$, among smokers $-26,2$ and $23,7 \%$, respectively $[4,5]$. The meta-analysis of series of randomized studies established that the prevalence of chronic obstructive pulmonary disease in the world and Europe is on average 7,2 \%, that is near four million and hundred people suffer from this disease, in city dwellers the prevalence of chronic obstructive pulmonary disease reaches $10,2 \%$, among men $-9,8 \%$ and women $-5,6 \%$ respectively, among patients, older than 40 years $-10 \%$, older than 65 years $-14,2 \%$, among smokers $-15,4 \%$, among persons, who never smoked $-4,3 \%$, among persons, who left smoking - 10,7 \% $[4,6,7]$.

The important factor that conditions the urgency of problem of chronic obstructive pulmonary disease is the high cost of this pathology for health protection system and society in whole. 
According to the data of Global Initiative for Chronic Obstructive Lung Disease (GOLD), in European countries the annual direct expenditures for chronic obstructive pulmonary disease reach 38,6 billion dollars and indirect ones exceed 17 billion dollars [4].

At the same time the tendency to growth of the number of patients with cardio-vascular diseases, especially, arterial hypertension that is the one of main causes of morbidity and invalidism of population as a result of its prevalence, is observed in the world. Arterial hypertension is registered with frequency $15-20 \%$ among adult population of the world and 30-60\% among patients of elder age group $[8,9]$. Arterial hypertension is an important risk factor of development of complication in cardio-vascular system, injury of target organs that determines morbidity and early invalidism of patients $[10,11]$.

In Ukraine there are almost 12 million persons with arterial hypertension and only $14 \%$ of them control the level of arterial pressure (AP) [12].

The scientists and doctors throughout the world deal with the problem of combination of chronic obstructive pulmonary disease and cardio-vascular system diseases. Thus, the ten-year retrospective analysis of the medical cards of stationary patients revealed that in $51,7 \%$ of patients with chronic obstructive pulmonary disease was diagnosed the diseases of cardio-vascular system, most frequent among them were coronary heart disease - in 28,9\%, heart failure - in $19,6 \%$, rhythm disorder - in $12,6 \%[1,13,14]$. The frequency of concomitant cardio-vascular disorders increased with age and had the close connection with sex, there was observed the increase of the number of men with combination of chronic obstructive pulmonary disease and coronary heart disease. At combined clinical course of chronic obstructive pulmonary disease and concomitant CVD the frequency of hospitalization increased because of any diseases during the year $[6,15]$.

Some scientists consider chronic obstructive pulmonary disease as an independent risk factor of cardio-vascular complications [16]. Among patients with chronic obstructive pulmonary disease the prevalence of heart failure is 2 times more, stable angina 2,5 times more, peripheral vessels diseases 2,4 more, stroke 1,5 times more comparing with general population [17, 18]. So the problem of diagnostic of chronic obstructive pulmonary disease in patients with arterial hypertension and coronary heart disease is today urgent and rather difficult that determines the topicality of our studies.

\section{Aim of research}

Estimation of the prevalence of chronic obstructive pulmonary disease among patients with coronary heart disease and arterial hypertension, who visited health protection institutions for medical help.

\section{Materials and methods}

The study was carried out in three stages. At the first stage the retrospective analysis of 15134 statistical medical cards of patients, who were on stationary treatment at therapeutic departments of the clinical hospital № 1 of Vinnytsia city during the period 2007-2009 were studied.

The other stage of the work was carried out in 2016 year. There was carried out the target diagnostics of chronic obstructive pulmonary disease of persons, who were on treatment at cardiologic department in 2016 for stable coronary heart disease and had not obstructive diseases of respiratory organs in anamnesis. The group of examination included 136 patients, mean age $(61,6 \pm 1,02)$ years, men - $109(80,1 \%)$, women - $27(19,9 \%)$. The diagnosis of coronary heart disease, verified by the results of coronography was in $78(57,3 \%)$ patients, by anamnesis data as to Q-myocardium infarction in $105(77,2 \%)$ patients, surgical interventions as myocardium revascularization in anamnesis were observed in 57 (41,9\%)patients, including stenting of coronary arteries $-42(30,8 \%)$ patients, aortacoronary bypass - $15(11 \%)$ patients. Smoking was indicated by $79(58 \%)$ patients, smoking index among smokers $(24,5 \pm 2,9)$ packet/years. The complicated professional anamnesis was in $33(24,2 \%)$ patients (Table 1). 
Table 1

Characteristic of examined persons

\begin{tabular}{|c|c|}
\hline Parameter $(n=136)$ & Results \\
\hline Number of patients & 136 \\
\hline Mean age, years & $61,6 \pm 1,02$ \\
\hline Men, abs., (\%) & $109(80,1 \%)$ \\
\hline Women, abs., (\%) & $27(19,9 \%)$ \\
\hline Post-infarction cardiosclerosis, abs., (\%) & $105(77,9 \%)$ \\
\hline Stable exertional angina, II functional class, abs., (\%) & $48(35,3 \%)$ \\
\hline Stable exertional angina, III functional class, abs., (\%) & $85(62,5 \%)$ \\
\hline Coronography, abs., (\%) & $78(57,3 \%)$ \\
\hline Stenting of coronary arteries, abs., (\%) & $42(30,8 \%)$ \\
\hline ACS, abs., (\%) & $15(11 \%)$ \\
\hline Hypertonic disease, abs., (\%) & $116(87,2 \%)$ \\
\hline Heart failure, I functional class, abs., (\%) & $5(3,6 \%)$ \\
\hline Heart failure, II functional class, abs., (\%) & $103(75,7 \%)$ \\
\hline Heart failure, III functional class, abs., (\%) & $25(18,3 \%)$ \\
\hline Diabetes mellitus, abs., (\%) & $20(14,7 \%)$ \\
\hline Obesity, abs., (\%) & $55(40,4 \%)$ \\
\hline Smoking, abs., (\%) & $79(58 \%)$ \\
\hline Complicated professional anamnesis, abs., (\%) & $33(24,2 \%)$ \\
\hline Complicated hereditary anamnesis as to chronic obstructive pulmonary disease, abs., (\%) & $5(3,7 \%)$ \\
\hline Complicated hereditary anamnesis as to coronary heart disease, abs., (\%) & $26(19,1 \%)$ \\
\hline
\end{tabular}

All patients, included in the study at the second stage of the work $(n=136)$, were interrogated by original questionnaire, created on the base of GOLD 2015 recommendations for diagnostics of chronic obstructive pulmonary disease [4] (Table 2).

Table 2

Questionnaire for diagnostics of chronic obstructive pulmonary disease

\begin{tabular}{ccc}
\hline Question questionnaire & Positive response & Negative response \\
\hline Do you have permanent cough several times a day? & Yes & No \\
Do you cough up sputum every day? & Yes & No \\
Do you have short breath more often than your coevals? & Yes & No \\
Your age is more than 40 years? & Yes & No
\end{tabular}

The patients also underwent computer spirography with bronchodilatation test using $400 \mathrm{mcg}$ of salbutamol (MasterScope ST) and interrogation by modified questionnaire of short breath assessment of medical research council (mMRC) and test of chronic obstructive pulmonary 
disease (CAT) for determination of clinical group of chronic obstructive pulmonary disease, regulated by the order by HPM of Ukraine № 555 of 27.05.2013 and GOLD recommendations.

Statistical processing of the data was carried out using the package of statistical programs STATISTICA10.0 and MicrosoftExel. The reliability of difference of values was calculated by non-parametric method by $\chi^{2}$ Pearson's criterion, U-test by Mann-Whitney and Student t-criterion at comparison of mean values.

\section{Results of research}

According to the results of the first retrospective stage of the work, it was established, that in period 2007-2009 at therapeutic departments of the hospital were treated 15134 patients, (8775 men $(57,9 \%)$ and 6359 women (42,1\%)). Among all patients 1538 patients with chronic obstructive pulmonary disease $10,2 \%$ had concomitant arterial hypertension. Among men the prevalence of combination of chronic obstructive pulmonary disease with arterial hypertension was diagnosed in 880 patients $(10,02 \%)$, among women - in $658(10,4 \%)$.

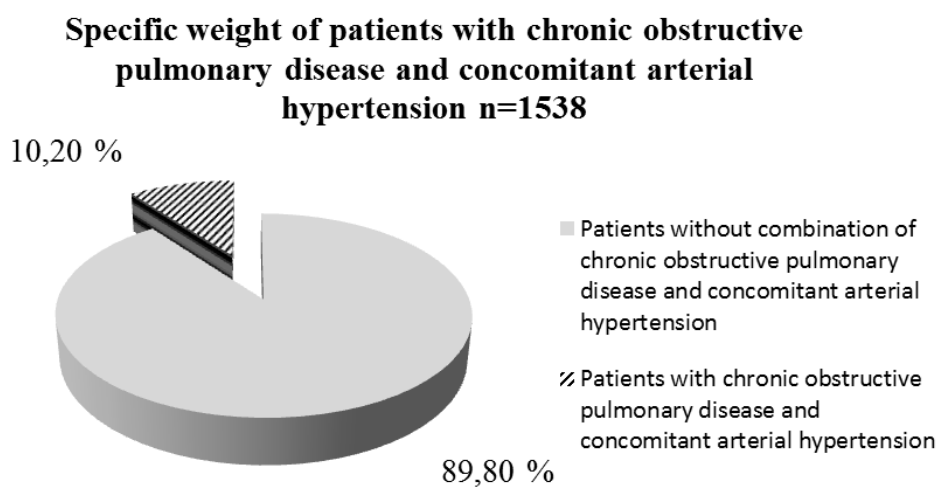

Fig. 1. Part of patients, treated at therapeutic departments of $\mathrm{MCH}$ № 1 during the period 2007-2009, and had combination of chronic obstructive pulmonary disease and concomitant arterial hypertension

The stable tendency to growth of the number of patients with combined pathology is observed annually. The growth of part of patients with polymorbid pathology has progressive character. Thus, in 2007 it was $8,17 \%$, in $2008-10,9 \%$, in $2009-12,42 \%$ (Fig. 2).

\section{Prevalence of combined course of chronic obstructive pulmonary} disease and arterial hypertension

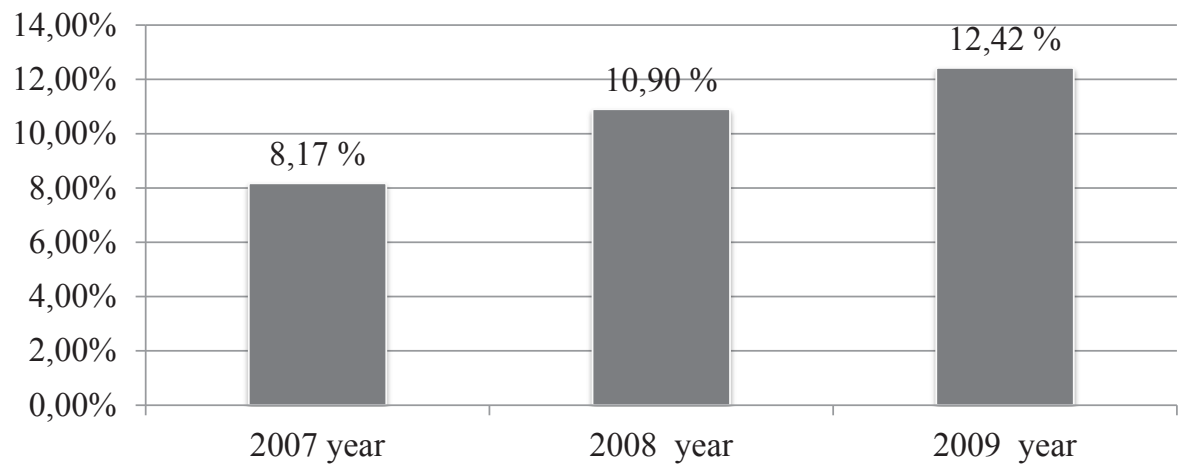

Fig. 2. Prevalence of combination of chronic obstructive pulmonary disease and cardio-vascular diseases at therapeutic departments of municipal hospital

There is observed certain tendency as to distribution of chronic obstructive pulmonary disease and arterial hypertension in different sex groups. Especially, in 2007 the prevalence of patients 
with such combination was more among women than among men. Whereas in 2008 and 2009 men prevailed, that has a tendency to growth.

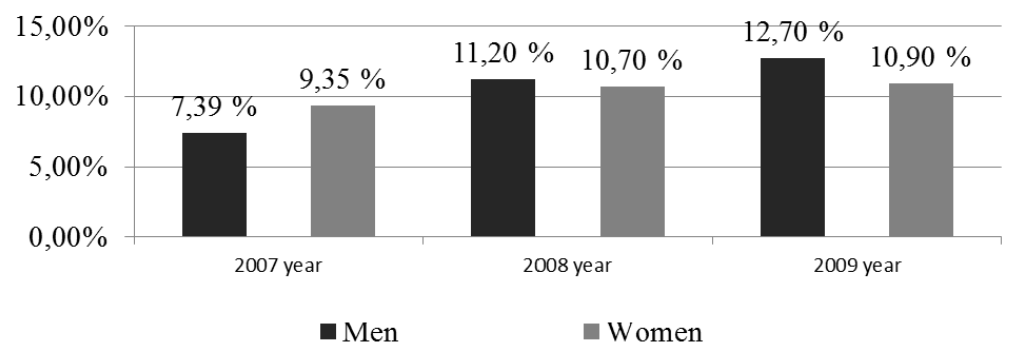

Fig. 3. Frequency of combination of chronic obstructive pulmonary disease and arterial hypertension at therapeutic departments of municipal hospital among men and women during the period 2007-2009

Most patients with comorbid pathology were hospitalized at pulmonological department, especially $1051(68,3 \%)$ persons, whereas at cardiologic one were 326 patients $(21,2 \%)$ and at therapeutic one -161 persons $(10,5 \%)$.

According to the results of second stage of questionnaire work, it was established, that the positive answers to the questions of the questionnaire were given by all 136 patients with stable coronary heart disease. Among the interrogated patients $3(2,2 \%)$ gave the positive answer to only 1 question, $50(36,7 \%)$ persons - to 2 questions, 61 (44,9\%) - to 3 questions, $17(12,5 \%)$ patients - o 4 questions and $5(3,7 \%)$ persons - to all 5 questions of the questionnaire, respectively. It must be noted that $80(58,8 \%)$ interrogated persons gave the positive answer to 3 and more questions, so they have clinical symptoms, typical for combination of chronic obstructive pulmonary disease.

All patients underwent spirometry with bronchodilitation test. According to its results, combination of chronic obstructive pulmonary disease was diagnosed in 36 (26,4\%) patients with stable coronary heart disease, mean age $(62 \pm 1,9)$ years (Fig. 4).

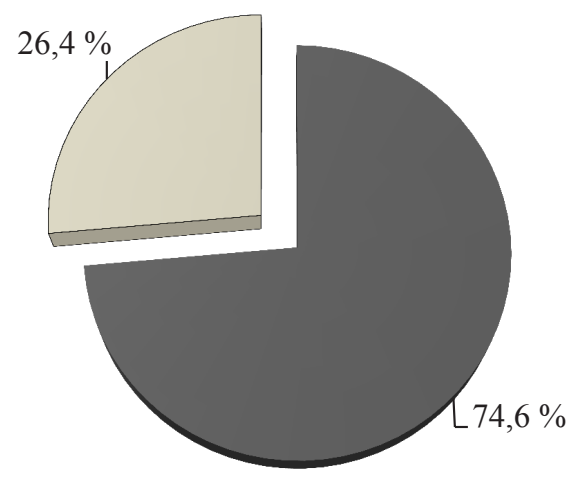

- Patients with coronary heart disease, $\mathrm{n}=100$, mean age $(61,2 \pm 1,2)$ years

$\square$ Patients with coronary heart disease and chronic obstructive pulmonary disease, $\mathrm{n}=36$, mean age $(62 \pm 1,9)$ years

Fig. 4. Frequency of revelation of chronic obstructive pulmonary disease among patients with stable coronary heart disease, $n=136$

We analyzed two groups of patients, I included 36 persons with coronary heart disease with concomitant chronic obstructive pulmonary disease and II included 100 persons with coronary heart disease without diagnosed chronic obstructive pulmonary disease. Although the patients of both groups were of the same age, there is observed the tendency to most frequent manifestation of chronic obstructive pulmonary disease among men $(91,7 \%$ and $76 \%$ respectively, $\mathrm{p}=0,07)$, who had more severe functional class of angina $(69,4 \%$ and $61 \%, \mathrm{p}=0,12)$, reliably more often after aortocoronary bypass $(22,2 \%$ and $7 \%, \mathrm{p}=0,04)$ and had heart failure of III functional class $(30,6 \%$ and $14 \%, p=0,03)$. The diagnosis of heart failure of III functional class in patients of this category can be explained by underestimation of the symptoms of chronic obstructive pulmonary disease, 
because short breath was assessed by doctors as a sign of heart failure. Among patients of I group comparing with two group was observed the tendency to more frequency of other concomitant diseases, namely hypertonic disease $(88,9 \%$ and $84 \%$ respectively, $\mathrm{p}=0,22)$, diabetes mellitus $(25 \%$ and $11 \%, \mathrm{p}=0,06)$,obesity $(47,2 \%$ and $38 \%, \mathrm{p}=0,08)$ (Table 3 ).

Table 3

Characteristic of patients with stable coronary heart disease and concomitant chronic obstructive pulmonary disease and patients with stable coronary heart disease without concomitant chronic obstructive pulmonary disease

\begin{tabular}{|c|c|c|}
\hline Characteristic & $\begin{array}{l}\text { I group patients with stable coronary } \\
\text { heart disease and concomitant chronic } \\
\text { obstructive pulmonary disease, } n=36\end{array}$ & $\begin{array}{l}\text { II group patients with } \\
\text { stable coronary heart } \\
\text { disease } n=100\end{array}$ \\
\hline Mean age, years & $62 \pm 1,9$ & $61,2 \pm 1,2$ \\
\hline Men, abs., (\%) & $33(91,7 \%)$ & $76(76 \%)$ \\
\hline Women, abs., (\%) & $3(8,3 \%)$ & $21(21 \%)$ \\
\hline Post-infarction cardiosclerosis, abs., (\%) & $26(72,2 \%)$ & $79(79 \%)$ \\
\hline Stable exertional angina, II functional class, abs., (\%) & $11(30,5 \%)$ & $37(37 \%)$ \\
\hline Stable exertional angina, III functional class, abs., (\%) & $25(69,4 \%)^{*}$ & $60(60 \%)^{*}$ \\
\hline Coronography, abs., (\%) & $17(47,2 \%)$ & $61(61 \%)$ \\
\hline Stenting of coronary arteries, abs., (\%) & $8(22,2 \%)$ & $34(34 \%)$ \\
\hline ACS, abs., (\%) & $8(22,2 \%)^{*}$ & $7(7 \%)^{*}$ \\
\hline Hypertonic disease, abs., (\%) & $32(88,9 \%)$ & $84(84 \%)$ \\
\hline Heart failure, I functional class, abs., (\%) & 0 & $5(5 \%)$ \\
\hline Heart failure, II functional class, abs., (\%) & $25(69,4 \%)$ & $78(78 \%)$ \\
\hline Heart failure, III functional class, abs., (\%) & $11(30,6 \%)$ & $14(14 \%)$ \\
\hline Diabetes mellitus, abs., (\%) & $9(25 \%)$ & $11(11 \%)$ \\
\hline Obesity, abs., (\%) & $17(47,2 \%)$ & $38(38 \%)$ \\
\hline Smoking, abs., (\%) & $27(75 \%)$ & $51(51 \%)$ \\
\hline
\end{tabular}

Note: *-difference between groups is reliable, $p<0,05$, calculation was carried out using Pearson $\chi^{2}$ criterion

Patients with coronary heart disease and firstly diagnosed chronic obstructive pulmonary disease were distributed by the clinical groups of chronic obstructive pulmonary disease. Among 36 patients with stable coronary heart disease and chronic obstructive pulmonary disease $9(25 \%)$ patients were included in the group A, that is the patients with metasymptom course and low risk of complications, 17 (47,2\%) patients - in group B that is the patients with many symptoms of chronic obstructive pulmonary disease and low risk of complications, $2(5,6 \%)$ patients - in group C, who have little number of symptoms and high risk of complications, 8 (22,2\%) patients formed D group, they had many clinical symptoms of chronic obstructive pulmonary disease and high risk of complications.

\section{Discussion of results}

The analysis revealed the essential layer of patients, who had combination of chronic obstructive pulmonary disease and stable coronary heart disease and arterial hypertension. Such comorbidity is noted by the scientists of different countries. It can be explained by the series of factors, namely: essential ageing of population, spreading of risk factors, influence of professional and everyday factors $[12,14,19]$. The same factors play the essential role in formation of cardio-vascular diseases. At the same time it must be noted that the concrete data as to the prevalence of chronic 
obstructive pulmonary disease in patients with cardio-vascular diseases are absent. Thus, the prevalence of arterial hypertension in persons with chronic obstructive pulmonary disease varies from 16 to $75 \%$ according to the data of different scientists $[17,19]$.

The complications of diagnostics of these combined diseases appear as a result of late resort to medical help, little number of symptoms at early stages of disease. It must be also noted that patients' complaints are often considered by doctors as manifestations of other diseases, for example, heart failure but not of chronic obstructive pulmonary disease.

Despite the stereotype literary data about the prevalence of men among patients with combined clinical course, we established the tendency to the growth of women number with cardio-vascular pathology at the background of chronic obstructive pulmonary disease. Especially, the prevalence of combined course among men and women in 2007 was 7,39\% and 9,35\% respectively, in $2008-11,2 \%$ and $10,7 \%$ respectively, in $2009-12,7 \%$ and $10,9 \%$ respectively [11].

The special complications take place in diagnostics of chronic obstructive pulmonary disease in patients with stable coronary heart disease, because in this group of patients the use of functional methods of examination, especially spirography with broncholithus is limited. This very point of view is shared by doctors of general practice. It is argued by the data about the influence of broncholithus on heart rate, electrolytic changes. So, it is important to elaborate the simple available screening methods that allow to select patients for further functional examination with high reliability degree [11, 20-22]. This very aim is set in our work.

It is worth attention, that in all patients, who gave 4 or 5 positive answers to the questions of the questionnaire, chronic obstructive pulmonary disease was diagnosed after examination of the function of external breath that testifies to the possibility of using this questionnaire to select patients with coronary heart disease for spirometry that is expedient for timely diagnostics of chronic obstructive pulmonary disease. Undoubtedly, our research is today limited only by retrospective analysis and examination of the small group of patients with stable coronary heart disease. Our further observations and studies will allow widen the data as to the features of course of chronic obstructive pulmonary disease in different categories of patients.

\section{Conclusions}

1. Thus, there is a numerous general therapeutic group of patients with diagnosed combination of chronic obstructive pulmonary disease with arterial hypertension, namely $-10,2 \%$.

2. According to the data of retrospective analysis, there is observed the progressive growth of the number of persons with combined pathology, namely chronic obstructive pulmonary disease with arterial hypertension from 2007 to 2009 year from 8,17\% to 12,42\%. These patients visit a pulmonologist most often.

3. Chronic obstructive pulmonary disease was diagnosed in $36(26,4 \%)$ patients after the target diagnostics among ones with stable coronary heart disease, who had not obstructive diseases of respiratory organs in anamnesis.

4. It was noted, that chronic obstructive pulmonary disease of A and B groups that had the low level of unfavorable events development was diagnosed in $26(72,2 \%)$ patients and in $10(27,8 \%)-\mathrm{C}$ and $\mathrm{D}$ groups, associated with the high risk of unfavorable changes and complications.

5. In the group of patients with previously non-diagnosed chronic obstructive pulmonary disease prevail men $(91,7 \%)$, smokers $(75 \%)$ with other concomitant diseases, especially arterial hypertension (88,9\%), obesity $(47,2 \%)$, diabetes mellitus $(25 \%)$.

\section{References}

[1] Westerik, J. A. M., Metting, E. I., van Boven, J. F. M., Tiersma, W., Kocks, J. W. H., Schermer, T. R. (2017). Associations between chronic comorbidity and exacerbation risk in primary care patients with COPD. Respiratory Research, 18 (1), 31. Available at: https:/www.ncbi.nlm.nih.gov/pmc/articles/ PMC5294875 doi: 10.1186/s12931-017-0512-2

[2] Gupta, M. (2011). Pattern of Comorbidities in hospitalized elderly patient of chronicobsrtuctive pulmonary disease. Journal of The Indian Academy of Geriatrics, 7, 6-11. 
[3] Ye, C., Younus, A., Malik, R., Roberson, L., Shaharyar, S., Veledar, E. et. al. (2016). Subclinical cardiovascular disease in patients with chronic obstructive pulmonary disease: a systematic review. QJM, 18, hcw135. doi: 10.1093/qjmed/hcw135

[4] Global Initiative for Chronic Obstructive Lung Disease. Available at: http://www.goldcopd.com

[5] Yin, P., Wang, H., Vos, T., Li, Y., Liu, S., Liu, Y. et. al. (2016). A Subnational Analysis of Mortality and Prevalence of COPD in China From 1990 to 2013. Chest, 150 (6), 1269-1280. doi: 10.1016/ j.chest.2016.08.1474

[6] Mooe, T., Stenfors, N. (2014). The Prevalence of COPD in Individuals with Acute Coronary Syndrome: A Spirometry-Based Screening Study. COPD: Journal of Chronic Obstructive Pulmonary Disease, 12 (4), 453-461. doi: 10.3109/15412555.2014.974742

[7] Geldmacher, H., Biller, H., Herbst, A., Urbanski, K., Allison, M., Buist, A. et. al. (2008). The prevalence of chronic obstructive pulmonary disease (COPD) in Germany. DMW - Deutsche Medizinische Wochenschrift, 133 (50), 2609-2614. doi: 10.1055/s-0028-1105858

[8] Roversi, S., Roversi, P., Spadafora, G., Rossi, R., Fabbri, L. M. (2013). Coronary artery disease concomitant with chronic obstructive pulmonary disease. European Journal of Clinical Investigation, 44 (1), 93-102. doi: 10.1111/eci.12181

[9] Cordero, A., Bertomeu-Martinez, V., Mazon, P., Facila, L., Bertomeu-Gonzalez, V., Cosin, J. et. al. (2011). Factors Associated With Uncontrolled Hypertension in Patients With and Without Cardiovascular Disease. Revista Espanola de Cardiologia, 64 (7), 587-593. doi: 10.1016/j.rec.2011.03.007

[10] Miliutina, O. V., Chicherina, E. N. (2009). Rol khronicheskogo vospalitelnogo protsessa v progressirovanii aterosklerosa u patsientov s khronicheskoi obstruktivnoi bolezniu legkikh v sochetanii s arterialnoi hipertoniei. Pulmonolohiya, 3, 43-46.

[11] Rabahi, M., Alves Pereira, S., Rodrigues Junior, J. L., Rezende, A. P., Castro da Costa, A., Sousa Correa, K., Conde, M. B. (2015). Prevalence of chronic obstructive pulmonary disease among patients with systemic arterial hypertension without respiratory symptoms. International Journal of Chronic Obstructive Pulmonary Disease, 10 (1), 1525-1529. doi: 10.2147/copd.s85588

[12] Pertseva, T. O., Gashynova, K. Yu., Yefimova, N. O. (2010). Pokaznyky funktsii endotelijyu y cholovikiv, shcho paliat, iz khronichnym obstruktyvnym zakhvoriuvannam legen [Indices of endotheial functions in males, smokers with chronic obstructive pulmonary disease]. Medychni perspectyvy, 3, 36-40.

[13] Bolton, C. E., Quint, J. K., Dransfield, M. T. (2016). Cardiovascular disease in COPD: time to quash a silent killer. The Lancet Respiratory Medicine, 4 (9), 687-689. doi: 10.1016/s2213-2600(16)30243-0

[14] Griffo, R., Spanevello, A., Temporelli, P. L., Faggiano, P., Carone, M., Magni, G. et. al. (2017). Frequent coexistence of chronic heart failure and chronic obstructive pulmonary disease in respiratory and cardiac outpatients: Evidence from SUSPIRIUM, a multicentre Italian survey. European Journal of Preventive Cardiology, 24 (6), 567-576. doi: 10.1177/2047487316687425

[15] Shilov, A. (2009). Osobennosti lechenija IBS v sochetanii s KHOBL. Lechashchij vrach, 7, 44-48.

[16] Andell, P., Koul, S., Martinsson, A., Sundstrom, J., Jernberg, T., Smith, J. G. et. al. (2014). Impact of chronic obstructive pulmonary disease on morbidity and mortality after myocardial infarction. Open Heart, 1 (1), e000002. Available at: www.ncbi.nlm.nih.gov/pmc/articles/PMC4189340/ doi: 10.1136/ openhrt-2013-000002

[17] VandeBorne, P., Wauters, A., Parati, G. (2012). Air pollution and hypertention. European Society of Hypertention Scientific Newsletter: Updateon Hypertention Management, 12, 51-52.

[18] Hua, C., Dong-Mei, M., Zhi-Min, W., Jian-Fang, C., Yi, L., Ai-Min, L., Fan, L. (2012). Prevalence of cardiovascular disease in subjects hospitalized due to chronic obstructive pulmonary disease in Beijing from 2000 to 2010. Journal of Geriatric Cardiology, 9 (1), 5-10. doi: 10.3724/sp.j.1263.2012.00005

[19] Karoli, N. A., Borodkin, A. V., Rebrov, A. P. (2015). Certain problems of diagnostics of chronic cardiac insufficiency in patients with chronic obstructive pulmonary disease. Klin Med (Mosk), 93 (5), 50-56.

[20] Karrasch, S., Bruske, I., Smith, M. P., Thorand, B., Huth, C., Ladwig, K.-H. et. al. (2016). What is the impact of different spirometric criteria on the prevalence of spirometrically defined COPD and its comorbidities? Results from the population-based KORA study. International Journal of Chronic Obstructive Pulmonary Disease, 11, 1881-1894. doi: 10.2147/copd.s104529

[21] Kaplan, A., Thomas, M. (2017). Screening for COPD: the gap between logic and evidence. European Respiratory Review, 26 (143), 160113. Available at: http://err.ersjournals.com/content/26/143/160113. long doi: 10.1183/16000617.0113-2016

[22] Ostrovskyi, M. M. (2011). Bronkhoobstruktyvnui syndrom: aktualni pytannia diagnostyky ta likuvannja. Ukraynskyy Pulmonolohichnyi zhurnal, 2, 14-16. 